\title{
Formation and characterization of Y : 247 film through spray pyrolysis technique
}

\author{
SUMAN ANAND* and O N SRIVASTAVA \\ Department of Physics, Banaras Hindu University, Varanasi 221 005, India \\ *Present address: Optical Radiation Standards, National Physical Laboratory, New Delhi 110 012, India
}

MS received 8 May 2002; revised 17 February 2004

\begin{abstract}
The synthesis of high temperature superconducting films of $Y: 247\left(T_{\mathrm{c}} \sim 73 \mathrm{~K}\right)$ have been successfully achieved. The difficulty in synthesis owing to narrow range of stability of $Y: 247$ has been taken care of through several quenching modes, e.g. quenching of the films synthesized at $\sim 850^{\circ} \mathrm{C}$, in air or in liquid nitrogen. The energy dispersive analysis of $\mathrm{X}$-rays (EDAX) and transmission electron microscopy (TEM) studies of the as processed film, $\mathrm{Y}_{2} \mathrm{Ba}_{4} \mathrm{Cu}_{7} \mathrm{O}_{14+x}$, exhibit nearly correct cationic stoichiometry of $2: 4: 7$; also narrow regions $(<50 \AA$ ) of minority $\mathrm{Y}: 124$ phase and stacking faults capable of working as flux pinning sites have been invariably found to be present. In addition to $\mathrm{Y}: 247, \mathrm{Ag}$ admixed films have also been investigated. The $T_{\mathrm{c}}$ here is $\sim 70-75 \mathrm{~K}$ which is similar to that of the film without silver. Representative estimates of transport critical current density $\left(J_{c}\right)$ for $\mathrm{Y}: 247 \mathrm{films}$ is $\sim 10^{3} \mathrm{~A} / \mathrm{cm}^{2}$, and with silver corresponding to $\mathrm{Y}_{2} \mathrm{Ba}_{4} \mathrm{Cu}_{7} \mathrm{O}_{14+x}$ $\left(\mathrm{Ag}_{0.1}\right)$ is found to be $\sim 10^{4} \mathrm{~A} / \mathrm{cm}^{2}$.
\end{abstract}

Keywords. Thin film; quenching; superconducting.

\section{Introduction}

Three high-temperature superconductors are found to exist in the $\mathrm{Y}-\mathrm{Ba}-\mathrm{Cu}-\mathrm{O}$ HTSC family. Their chemical formulae may be written as $\mathrm{Y}_{2} \mathrm{Ba}_{4} \mathrm{Cu}_{6+n} \mathrm{O}_{14+n}$, where $n$ is the average number of $\mathrm{CuO}$ 'chains' separating two $\mathrm{CuO}_{2}$ 'planes' in each basic building block. The $n=0$ member of the family ('Y : 123') is the well known superconductor $\left(T_{\mathrm{c}} \sim 90 \mathrm{~K}\right)$. In contrast to $\mathrm{Y}: 123$, the $n=2$ member of the YBCO family ('Y : 124') is characterized by high stability of the oxygen concentration. In a co-existing manner, its critical temperature $\left(T_{\mathrm{c}}\right), 81-82 \mathrm{~K}$, is quite stable (Karpinski et al 1990). The $n=1$ member of this family i.e. $\mathrm{Y}_{2} \mathrm{Ba}_{4} \mathrm{Cu}_{7} \mathrm{O}_{14+x}$, was first synthesized under high oxygen pressure by Karpinski et al (1998). The $\mathrm{Y}: 123, \mathrm{Y}: 124$ and $\mathrm{Y}: 247$ phases of $\mathrm{Y}-\mathrm{Ba}-\mathrm{Cu}-\mathrm{O}$ along with their rare earth analogues offer three isostructural families with incremental variations in the lattice parameters, superconducting properties and potential advantages. Bordet et al (1998) determined the crystal structure of $\mathrm{Y}: 247$, the structure contains alternating blocks with $\mathrm{Cu}-\mathrm{O}$ single chains ( $\mathrm{Y}: 123$ units) and $\mathrm{Cu}-\mathrm{O}$ double chains ( $Y: 124)$ units in the $c$ direction.

$\mathrm{Y}: 247$ can be prepared in a similar fashion as $\mathrm{Y}: 124$, by employing oxygen enhancer catalysts or under high oxygen pressures, the primary differences between the

*Author for correspondence two preparation methods being the sintering temperature which in the case of $\mathrm{Y}: 247$ is between $845^{\circ} \mathrm{C}$ and $870^{\circ} \mathrm{C}$ i.e. at intermediate temperature between those of $\mathrm{Y}: 123$ and $\mathrm{Y}: 124$. As is well known, $\mathrm{Y}_{1} \mathrm{Ba}_{2} \mathrm{Cu}_{3} \mathrm{O}_{7-\delta}$ has a variable oxygen stoichiometry, $0 \leq \delta \leq 1$, due to labile oxygen in the chain layer. In contrast, $\mathrm{Y}_{1} \mathrm{Ba}_{2} \mathrm{Cu}_{4} \mathrm{O}_{8}$ has a fixed oxygen stoichiometry $(\delta=0)$ due to the stable $-\mathrm{Cu}_{2} \mathrm{O}_{2}$ ribbons. The Y : 247 phase has only about half the expansion anomaly of $\mathrm{Y}: 123$ and suffers from nearly half the oxygen unloading shortcoming. Even more importantly, the material remains orthorhombic across the whole oxygen stoichiometric range and, therefore, is free from the rather subtle tetragonal to orthorhombic transition which is the cause of extensive microcracking in $\mathrm{Y}: 123$. Another interesting aspect of $\mathrm{Y}: 247$ phase seems to be the fact that unlike $\mathrm{Y}: 123$ and $\mathrm{Y}: 124$, the as grown phase of this HTSC material invariably contains some amount (few unit cell wide regions) of $Y: 124$. This second phase may be useful since it may act as flux pinning sites as it possesses the desired properties e.g. extent of few unit cells only. The Y: 124 phase has $T_{\mathrm{c}}$ close to $80 \mathrm{~K}$, while that of $\mathrm{Y}: 247$ depends on the oxygen stoichiometry and according to earlier reports has been observed at temperatures higher than $90 \mathrm{~K}$ (Tallon et al 1990). These features distinguish Y:247 from its counterparts $\mathrm{Y}: 123$ and $\mathrm{Y}: 124$, and imparts special characteristics in regard to deployment for applications. As is well known now, thin films are better suited for a variety of applications. These applications include superconducting quantum interfer- 
ence devices (SQUIDs), superconducting interconnects and microwave application and in the measurement of their basic intrinsic properties. The most extensive studies on thin films employing both the conventional (e.g. chemical techniques like spray pyrolysis) as well as sophisticated techniques (e.g. laser ablation) have been carried out on Y:123 HTSC phase, some studies on thin films of Y : 124 have also been done (Guptasarma et al 1991; Kumari Suman et al 1996). However, hardly any studies on thin films of Y : 247 HTSC phase are available. In view of the lower variation of oxygen stoichiometry, absence of tetragonal to orthorhombic transition and the native presence of a minority $(\mathrm{Y}: 124)$ phase, interest in the synthesis and studies of $\mathrm{Y}: 247$ films is imperative. Keeping these facts in view, the present investigations on the formation, synthesis and characterization of $\mathrm{Y}: 247$ films have been undertaken. The chemical technique of spray pyrolysis which is simple to handle, economically viable and yet leads to a device grade HTSC film and also holds technical potential (Deluca et al 1993), has been employed for the formation of $\mathrm{Y}: 247$ films.

Since the films corresponding to Y : 247 HTSC phase have not been prepared earlier, the formation parameters are not known and Y : 247 has a narrow stability range of existence as compared to other HTSC phases of the series, $\mathrm{Y}_{2} \mathrm{Ba}_{4} \mathrm{Cu}_{6+n} \mathrm{O}_{14+n}$ (e.g. Y : 124, Y : 123). The conditions of the formation of $\mathrm{Y}: 247$ thin films have been determined in the present investigation based on a series of quenching experiments in air and liquid nitrogen, aimed at arresting the $\mathrm{Y}: 247$ phase in the as synthesized films. In addition to quenching experiments, several annealing experiments in oxygen ambient were carried out for oxygen loading, and for the optimization of the transition temperature, $T_{\mathrm{c}}$. The estimates of $J_{\mathrm{c}}$ for the Y : 247 and Y : $247\left(\mathrm{Ag}_{0.1}\right)$ films have also been obtained.

\section{Experimental and results}

Films of Y : 247 were prepared by downward spray of a $0.3 \mathrm{M}$ alcoholic solution containing the nitrates of $\mathrm{Y}, \mathrm{Ba}$ and $\mathrm{Cu}$ in the atomic ratio $2: 4: 7$, on single crystal $\mathrm{MgO}$ substrates. $5 \%$ of $\mathrm{NaNO}_{3}$ was added as oxygen enhancer. The substrate temperature $\left(T_{\mathrm{s}}\right)$ for deposition was kept at $450^{\circ} \pm 10^{\circ} \mathrm{C}$. The oxygen was used as the carrier gas and the deposition rate was $\sim 4 \mathrm{cc} / \mathrm{min}$. As prepared films on the substrate were annealed at $850^{\circ} \pm 5^{\circ} \mathrm{C}$ in $\mathrm{O}_{2}$ atmosphere for different durations: ranging from 5-24 h. Keeping in view the fact that $\mathrm{Y}: 247$ will convert into $\mathrm{Y}: 124$ at temperatures below $850^{\circ} \mathrm{C}$, in the first set of experiments the above annealed films were air quenched through quick withdrawal from the furnace. To have still better phase retention, in the second set of experiments the films were quenched in liquid nitrogen. The conversion of $\mathrm{Y}: 247$ into $\mathrm{Y}: 124$ is kinetically hindered below $\sim 650^{\circ} \mathrm{C}$; therefore, the samples were oxygen loaded by slow heating in oxygen at $\sim 550^{\circ} \mathrm{C}$ for $8 \mathrm{~h}$, to achieve proper oxygen stoichiometry.

The quenching was performed in the following way: each ceramic sample was contained in a alumina boat and was heated to $850^{\circ} \mathrm{C}$ in flowing $\mathrm{O}_{2}$. At quenching temperature $\left(T_{\mathrm{q}} \approx 850^{\circ} \mathrm{C}\right)$, the samples with the boat was withdrawn rapidly (in $<1 \mathrm{~s}$ ) and dropped directly into liquid nitrogen (LN), which was used because of its nonreactivity with the ceramic material. After quenching in LN, the film together with substrate was instantly heated to just above $100^{\circ} \mathrm{C}$ to get rid of any condensed moisture. Details of the main processing parameters embodying air or LN quenching and oxygen annealing (loading) are shown in tables 1 and 3 . In an effort to get better results and also to compare the effect of air or LN quenching, another set of experiments were carried out in which the quenched films were annealed in Argon atmosphere (table 2).

The gross phase identification was carried out using Philips PW-1710 power diffractometer with a wide-angle goniometer and graphite monochromator. The XRD of the samples annealed at $850^{\circ} \mathrm{C}$ in oxygen, air quenched and then annealed in $\mathrm{O}_{2}$ showed that in addition to $\mathrm{Y}: 247$, the other $\mathrm{Y}$ bearing phases i.e. $\mathrm{Y}: 124$ and $\mathrm{Y}: 123$, were also present. The comparative XRD patterns of the films annealed at $850^{\circ} \mathrm{C}$ in oxygen, quenched in air or LN and then subsequently annealed in Argon, are shown in figures $1 \mathrm{a}$ and $\mathrm{b}$. It exhibits that the phase is nearly $\mathrm{Y}: 247$ with some traces of $\mathrm{Y}: 124$ and $\mathrm{CuO}$. However, the XRD of the as grown samples annealed at $850^{\circ} \mathrm{C}$ in oxygen for $17 \mathrm{~h}$, quenched in LN and then finally oxygen loaded at

Table 1. Details of processing parameters embodying air quenching.

\begin{tabular}{lccccrc}
\hline $\begin{array}{l}\text { Annealing temp. } \\
\left( \pm 5^{\circ} \mathrm{C}\right)\end{array}$ & $\begin{array}{c}\text { Annealing } \\
\text { time in } \mathrm{O}_{2}(\mathrm{~h})\end{array}$ & $\begin{array}{c}\text { Quenching } \\
\text { medium }\end{array}$ & $\begin{array}{c}\text { Temp. } \\
\left( \pm 5^{\circ} \mathrm{C}\right)\end{array}$ & Ambient & $\begin{array}{c}\text { Annealing } \\
\text { time }\end{array}$ & $\begin{array}{c}T_{\mathrm{c}}(R=0) \\
\left({ }^{\circ} \mathrm{K}\right)\end{array}$ \\
\hline 850 & 5 & Air & 500 & Oxygen & $12 \mathrm{~h}$ & - \\
850 & 10 & Air & 500 & Oxygen & $12 \mathrm{~h}$ & $<20 \mathrm{~K}$ \\
850 & 12 & Air & 550 & Oxygen & $8 \mathrm{~h}$ & $<47 \mathrm{~K}$ \\
850 & 14 & Air & 550 & Oxygen & $8 \mathrm{~h}$ & $<20 \mathrm{~K}$ \\
850 & 17 & Air & 550 & Oxygen & $8 \mathrm{~h}$ & $<20 \mathrm{~K}$ \\
850 & 24 & Air & 550 & Oxygen & $8 \mathrm{~h}$ & $<20 \mathrm{~K}$ \\
\hline
\end{tabular}


Table 2. Dependence of $T_{\mathrm{c}}$ on quenching medium.

\begin{tabular}{lcccccc}
\hline $\begin{array}{l}\text { Annealing temp. } \\
\left( \pm 5^{\circ} \mathrm{C}\right)\end{array}$ & $\begin{array}{c}\text { Annealing } \\
\text { time in } \mathrm{O}_{2}(\mathrm{~h})\end{array}$ & $\begin{array}{c}\text { Quenching } \\
\text { medium }\end{array}$ & $\begin{array}{c}\text { Temp. } \\
\left( \pm 5^{\circ} \mathrm{C}\right)\end{array}$ & Ambient & $\begin{array}{c}\text { Annealing } \\
\text { time }\end{array}$ & $\begin{array}{c}T_{\mathrm{c}}(R=0) \\
\left({ }^{\circ} \mathrm{K}\right)\end{array}$ \\
\hline 850 & 12 & Air & 550 & Argon & $8 \mathrm{~h}$ & $\sim 60 \mathrm{~K}$ \\
850 & 12 & Liquid $\mathrm{N}_{2}$ & 550 & Argon & $8 \mathrm{~h}$ & $\sim 40 \mathrm{~K}$ \\
\hline
\end{tabular}

Table 3. Dependence of $T_{\mathrm{c}}$ on annealing time embodying liquid $\mathrm{N}_{2}$ quenching.

\begin{tabular}{lcccccc}
\hline $\begin{array}{l}\text { Annealing temp. } \\
\left( \pm 5^{\circ} \mathrm{C}\right)\end{array}$ & $\begin{array}{c}\text { Annealing } \\
\text { time in } \mathrm{O}_{2}(\mathrm{~h})\end{array}$ & $\begin{array}{c}\text { Quenching } \\
\text { medium }\end{array}$ & $\begin{array}{c}\text { Temp. } \\
\left( \pm 5^{\circ} \mathrm{C}\right)\end{array}$ & Ambient & $\begin{array}{c}\text { Annealing } \\
\text { time }\end{array}$ & $\begin{array}{c}T_{\mathrm{c}}(R=0) \\
\left({ }^{\circ} \mathrm{K}\right)\end{array}$ \\
\hline 850 & 14 & Liquid $\mathrm{N}_{2}$ & 550 & Oxygen & $8 \mathrm{~h}$ & $\sim 50 \mathrm{~K}$ \\
850 & 17 & ${\text { Liquid } \mathrm{N}_{2}}^{2}$ & 550 & Oxygen & $8 \mathrm{~h}$ & $\sim 73 \mathrm{~K}$ \\
850 & 24 & Liquid $\mathrm{N}_{2}$ & 550 & Oxygen & $8 \mathrm{~h}$ & $\sim 60 \mathrm{~K}$ \\
\hline
\end{tabular}

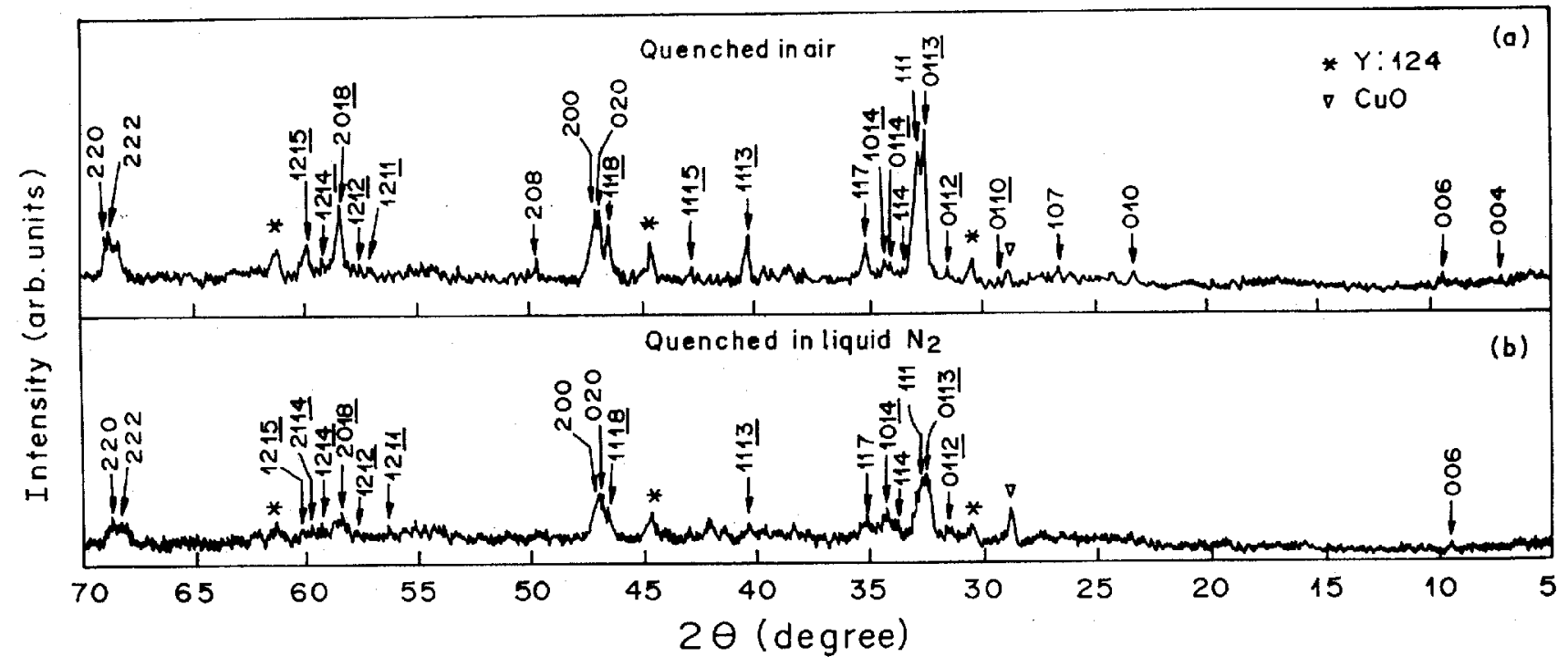

Figure 1. (a)-(b) XRD of $\mathrm{Y}: 247$ phase $\left(\sim 850^{\circ} \mathrm{C} ; 12 \mathrm{~h}\right.$, after air quenching, annealed in Argon at $\sim 550^{\circ} \mathrm{C}$ for $\left.8 \mathrm{~h}\right)$ exhibiting some traces of $\mathrm{Y}: 124$ and $\mathrm{CuO}$.

$550^{\circ} \mathrm{C}$, revealed better $\mathrm{Y}: 247$ phase formation evidenced through the presence of low angle reflections (e.g. 004, 006) of $\mathrm{Y}: 247$ as shown in figure 2.

Electrical characterization of the films was carried out using a Keithley resistivity set-up and an APD closed cycle refrigerator controlled by a computer. The $R-T$ measurements for as grown films annealed at $\sim 850^{\circ} \mathrm{C}$ for $12 \mathrm{~h}$ in $\mathrm{O}_{2}$, quenched in air or LN and then finally annealed in Argon showed $T_{\mathrm{c}}(R=0) \sim 60 \mathrm{~K}$ (curve a) and $\sim 40 \mathrm{~K}$ (curve b), respectively (figure 3 ). The curve $\mathrm{b}$ i.e. LN quenched and Argon annealed sample, exhibited semiconducting behaviour before transition. The representative $R-T$ curve obtained from the film annealed at $\sim 850^{\circ} \mathrm{C}$ for $\sim 17 \mathrm{~h}$ in $\mathrm{O}_{2}$, LN quenched and then finally oxygen loaded, exhibited pre-transition metallic behaviour and showed $T_{\mathrm{c}}(R=0)$ of $\sim 73 \mathrm{~K}$ (figure 4$)$. Following the same method applied for the synthesis of $Y: 247$ films, the silver bearing Y : 247 films were also prepared. However, for introducing $\mathrm{Ag}$, suitable amount of $0.3 \mathrm{M}$ $\mathrm{AgNO}_{3}$ solution in distilled water was added in the main solution. For the case of Ag bearing Y : 247 phase, a representative $R-T$ curve is shown in figure 5 , the $T_{\mathrm{c}}(R=0)$ corresponding to this curve comes out to be $\sim 75 \mathrm{~K}$.

For HTSC materials, which correspond to rather complex ceramic materials, in addition to the gross structure, monitoring of the local area structure and microstructures, are equally important. Keeping in view the fact that the transmission electron microscopy (TEM) is the most appropriate technique for the said purpose, we employed TEM technique both in imaging and diffraction modes (and also EDAX) for the exploration of local area structure/microstructure. A computerized electron microscope (Philips EM (CM-12)) was used both in imaging and diffraction modes for microstructural analysis. Samples for 


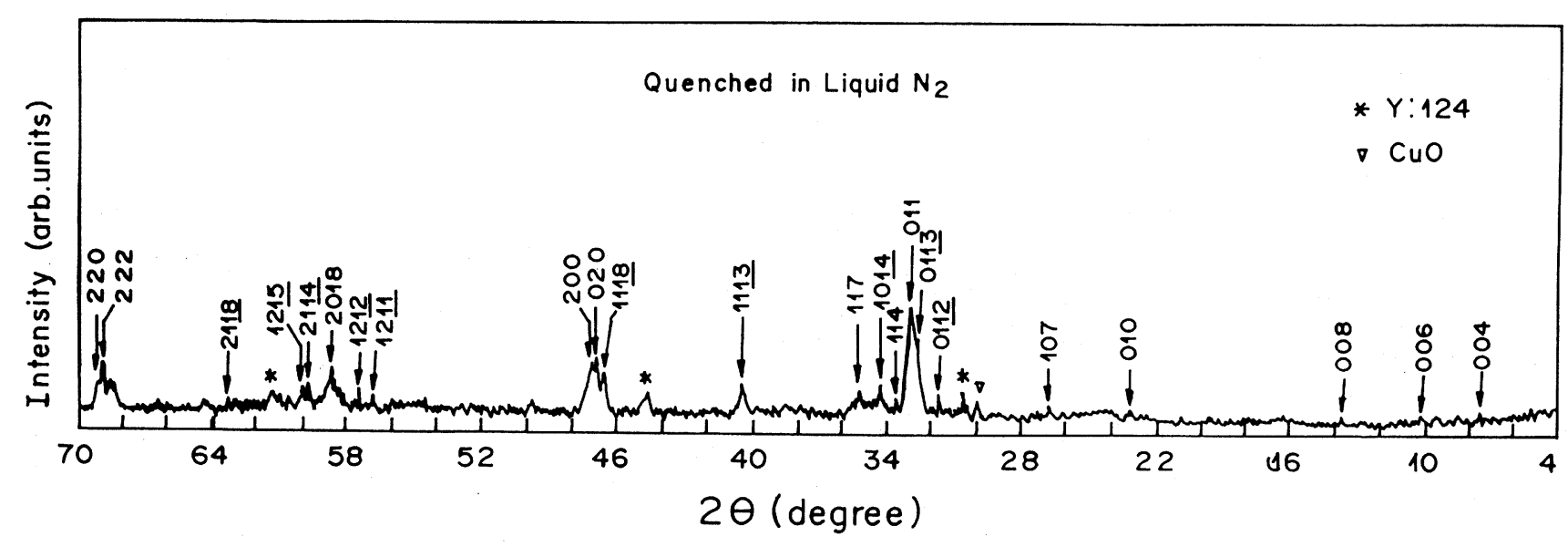

Figure 2. XRD pattern of the spray pyrolysed $\mathrm{Y}: 247$ phase $\left(\sim 850^{\circ} \mathrm{C} ; 17 \mathrm{~h}\right.$, oxygen loaded at $\left.\sim 550^{\circ} \mathrm{C}\right)$.

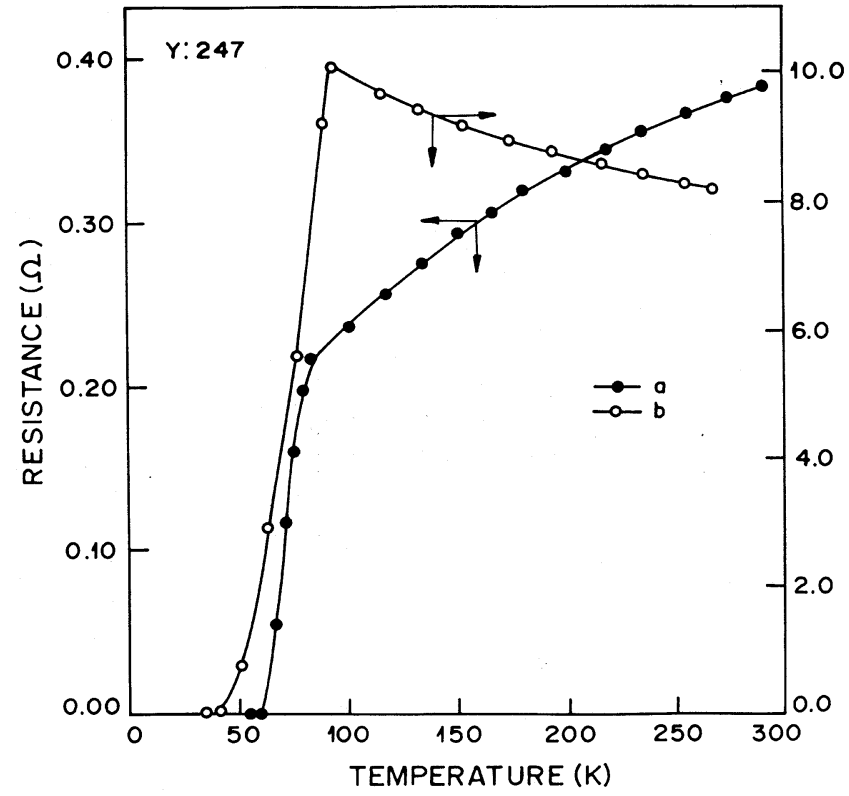

Figure 3. Temperature dependence of the resistance of (a) air quenched and (b) LN quenched, samples annealed in Argon.

TEM studies were made by scraping the as synthesized Y : 247 over carbon coated copper grids. Figure 6 shows EDAX of the processed $\mathrm{Y}: 247$ film. The composition ratio of $\mathrm{Y}: \mathrm{Ba}: \mathrm{Cu}$ as determined is approximately $2: 3 \cdot 5: 7 \cdot 3$. The EDAX results indicate good agreement with the envisaged 2:4:7 stoichiometry. A typical electron diffraction pattern and TEM image bringing out direct lattice resolution representative of the as processed sample are shown in figures 7 and 8, respectively. Figure 7a exhibits the SAD pattern, in which besides the sharp diffraction spots, a weak diffuse streaking along $c^{*}$ can also be seen. Yet another curious structural feature as revealed by the electron diffraction studies is the presence of a superstructural phase with $c^{\prime} \cong 4 c_{0}$ ( $c_{0}$ being the lattice parame-

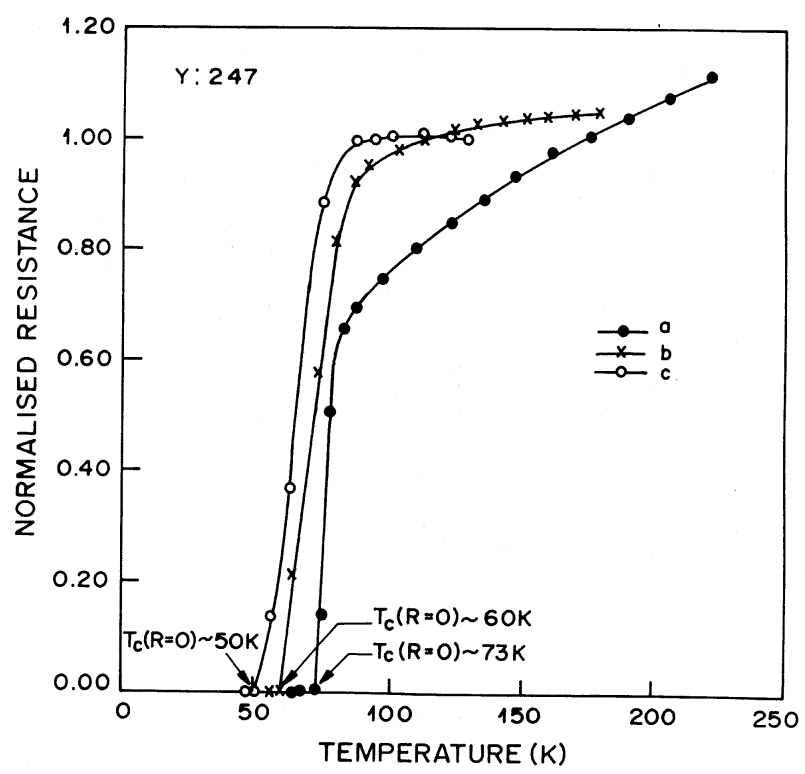

Figure 4. Variation of resistance with temperature for the films quenched in $\mathrm{LN}$ after annealing at $850^{\circ} \mathrm{C}$ in oxygen for (a) $17 \mathrm{~h}$, (b) $24 \mathrm{~h}$ and (c) $14 \mathrm{~h}$.

ter of the parent $\mathrm{Y}: 247$ phase). However, irrespective of streaking the presence of some closely spaced spots along the marked direction reflects the fact that unit cells of $c$ periodicity $\sim 50.8 \AA(c / 2 \approx 25.4 \AA)$ which corresponds to $\mathrm{Y}: 247$ phase, are present (figure $7 \mathrm{~b}$ ). Figure 8 shows that the minority phase i.e. $\mathrm{Y}: 124$ (B), is embedded in the $\mathrm{Y}: 247$ regions $(\mathrm{A})$.

\section{Discussion}

As mentioned earlier, the $\mathrm{Y}: 247$ structure consists of alternating Y: 123 and Y: 124 blocks. Due to the double $\mathrm{Cu}-\mathrm{O}$ chains the coordination of oxygen in $\mathrm{Cu}$ increases 
in the $\mathrm{Y}: 124$, therefore, the oxygen is more stable than in the $Y: 123$ structures. In $Y: 247$ the oxygen in the single chains i.e. in the $\mathrm{Y}: 123$ layers, is expected to be weakly bound, while the oxygen in the $\mathrm{Y}: 124$ layers is more tightly bound. Consequently, the oxygen loss on heating Y : 247 should be less than for $\mathrm{Y}: 123$ at the same temperature and oxygen partial pressure. In contrast to the Y : 123 phase, the Y : 247 HTSC phase remains superconducting (although with reduced $T_{\mathrm{c}}$ ) even after losing an appreciable amount of oxygen from the Y : 123 like blocks. At higher temperatures, the Y: 124 blocks are destroyed too, leaving the $\mathrm{Y}: 123$ and $\mathrm{CuO}$ as the only 'stable' products.

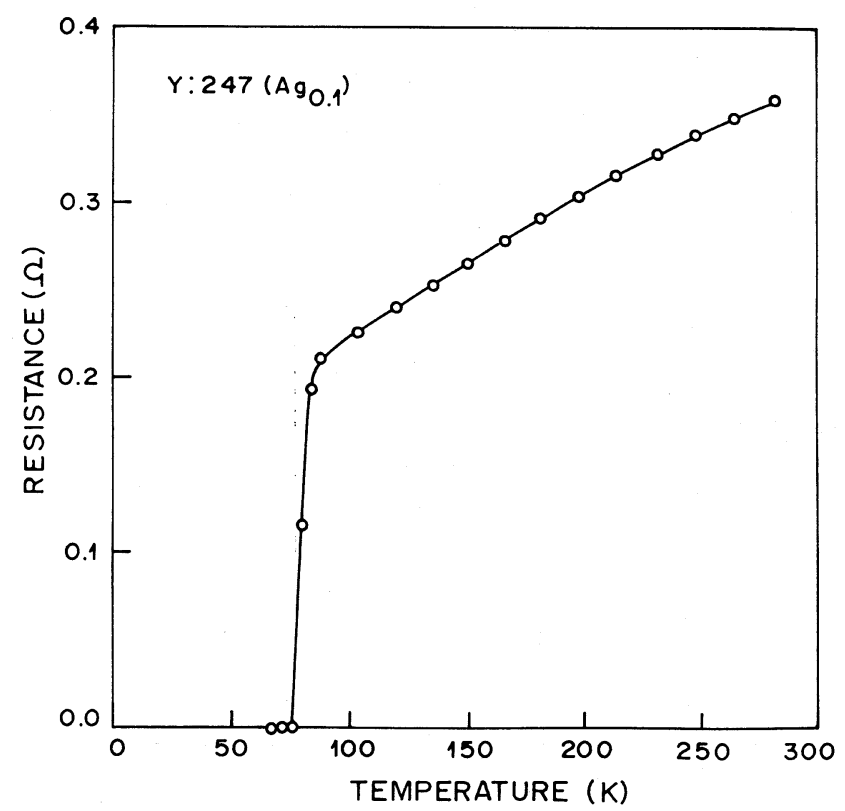

Figure 5. Variation of resistance with temperature for the $\mathrm{Ag}$ bearing $\mathrm{Y}: 247$ films corresponding to $\mathrm{Y}_{2} \mathrm{Ba}_{4} \mathrm{Cu}_{7} \mathrm{O}_{14+x}\left(\mathrm{Ag}_{0 \cdot 1}\right)$.

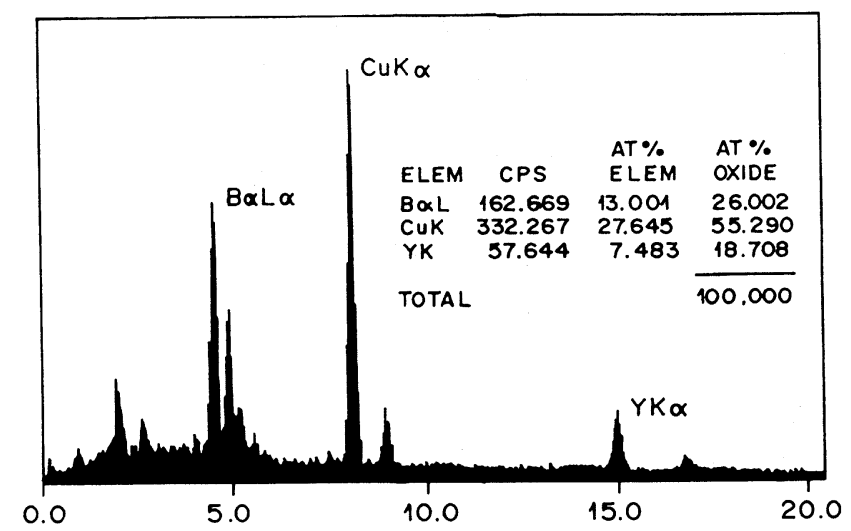

Figure 6. EDAX of $\mathrm{Y}: 247$ thin film exhibiting the nearly correct cationic stoichiometry.
The thermal stability of each of these three phases (Y : 123, Y : 247 and Y : 124) is different. During annealing of the $\mathrm{Y}: 124$ phase, a sudden decomposition with the formation of the $\mathrm{Y}: 123$ phase starts at about $880^{\circ} \mathrm{C}$. The $\mathrm{Y}: 124$ phase has very high thermal stability and the $\mathrm{Y}: 247$ phase is less stable than $\mathrm{Y}: 124$ (but more stable than $Y: 123)$ because of the existence of $Y: 123$ like blocks in the structure. These considerations reveal that $\mathrm{Y}: 247$ is an intermediate phase between $\mathrm{Y}: 123$ and $\mathrm{Y}: 124$ and also the formation of $\mathrm{Y}: 124$ and $\mathrm{Y}: 247$ phases occurs via intermediate multiphase reactions with strong consumption of oxygen. In the present investigation the samples annealed at $\sim 850^{\circ} \mathrm{C}$ for different time spans of 14,17 and $24 \mathrm{~h}$, have been quenched in liquid $\mathrm{N}_{2}$ so as to arrest the formed phases. Since the thermal mass of the sample i.e. substrate and film, is small, the temperature would drop from $\sim 850^{\circ} \mathrm{C}$ to nearly room temperature in a few seconds. It would thus be possible to freeze the phase prevalent at the processing temperature of $\sim 850^{\circ} \mathrm{C}$. The transition temperature, $T_{\mathrm{c}}$, of the $\mathrm{Y}: 247$ phase appears to vary in a wide range of $16-70 \mathrm{~K}$ (see tables $1-3$ ). This variation presumably arises due to varying oxygen content. On the other hand, $T_{\mathrm{c}}$ of $\mathrm{Y}: 124$ shows a very small deviation from $81 \mathrm{~K}$ (Kumari Suman et al 1996).

The critical current densities of the as-synthesized $\mathrm{Y}: 247$ films were measured on several samples. The representative estimate of $J_{\mathrm{c}}$ was found to be $\sim 2$ to $3 \times 10^{3} \mathrm{~A} / \mathrm{cm}^{2}$. The critical current density, $J_{c}$, for the $\mathrm{Y}_{2} \mathrm{Ba}_{4} \mathrm{Cu}_{7} \mathrm{O}_{14+x}$ $\left(\mathrm{Ag}_{0.1}\right)$ films was found to be $\sim 2 \times 10^{4} \mathrm{~A} / \mathrm{cm}^{2}$ i.e. about an order higher than the films without Ag. This is however, expected since in other $\mathrm{Y}$ bearing cuprate HTSC thin film phases e.g. $\mathrm{YBa}_{2} \mathrm{Cu}_{3} \mathrm{O}_{14+x}\left(\mathrm{Ag}_{y}\right)$ (Kumar et al 1993), $J_{\mathrm{c}}$ have been found to improve significantly with $\mathrm{Ag}$ doping. Further work on optimization of $J_{\mathrm{c}}$ including the effect of variation of $\mathrm{Ag}$ concentration is presently being carried out and results will be forthcoming.

In the present investigation attempts have been made to monitor the microstructural features by electron microscopy. From the microstructural investigations, it has been found that the as synthesized samples are generally biphasic. As a result of decomposition, Y:247 may be partially converted into $\mathrm{Y}: 124$. If the removal of a $\mathrm{Cu}-\mathrm{O}$ chain is random, there would be a stacking disorder along ' $c$ '. This disorder causes streaking in the diffraction pattern of the 001 rows of spots. The Y : 124 phase, if only few unit cells wide would have a much lower $T_{\mathrm{c}}$ than the usual bulk $\mathrm{Y}: 124$. Thus narrow $\mathrm{Y}: 124$ regions which would be compatible with the coherence length $(\sim 30 \AA)$ are expected to act as flux pinning sites. Similarly stacking faults in the $\mathrm{Y}: 247$ matrix (see figure 8) having widths of the order of coherence length would also act as flux pinning centres. The representative TEM image shown in figure 8 brings out the fact that narrow regions having extents of about the coherence length are present corresponding to both the Y:124 and stacking faults. 

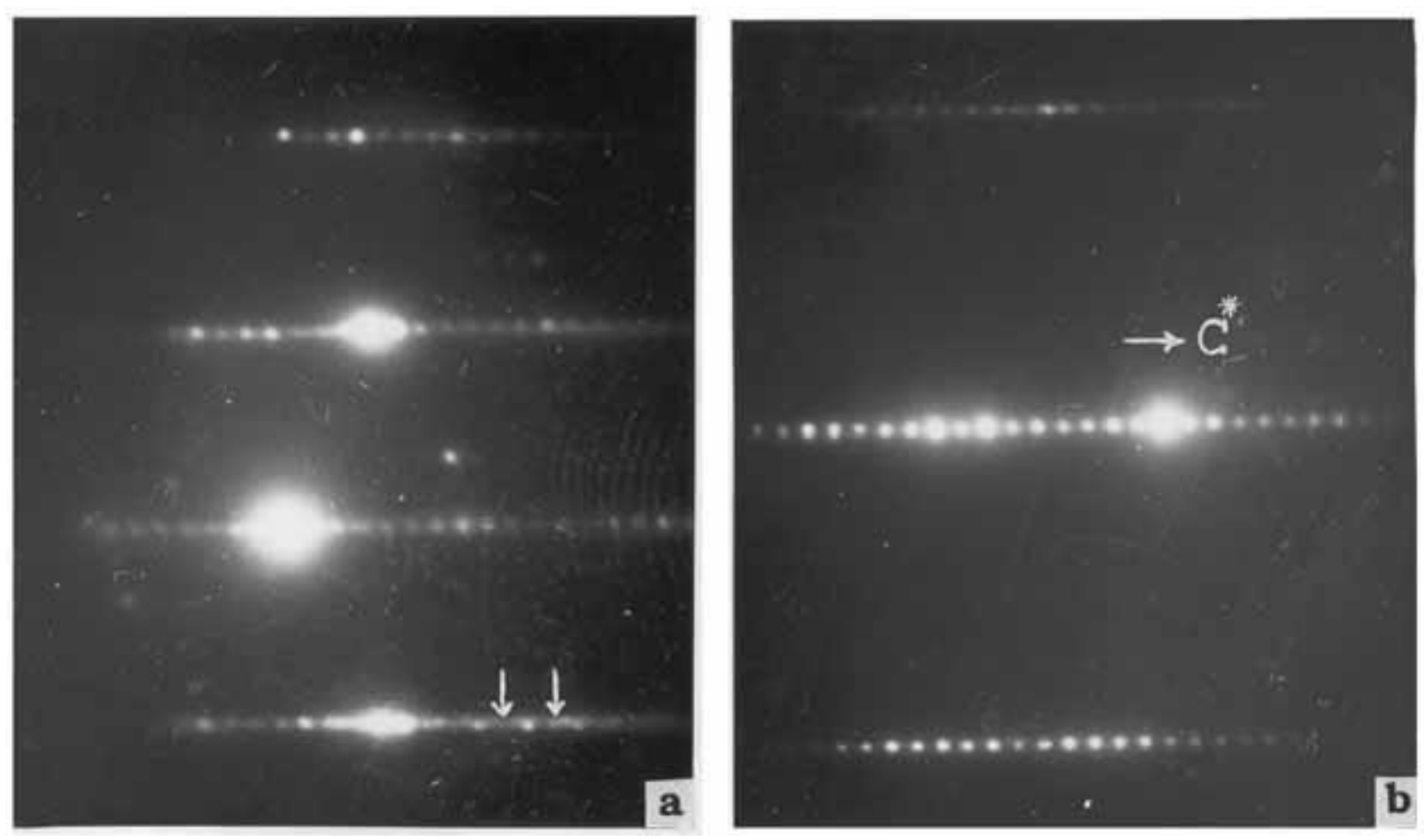

Figure 7. (a) SAD pattern exhibiting disorder through diffuse streaking along the $c^{*}$ axis and superstructures $\left(c^{\prime} \approx 4 \mathrm{C}_{0}\right)$ marked by arrow and (b) a representative SAD pattern of $\mathrm{Y}: 247$ showing $c / 2 \approx 25.4 \AA$.

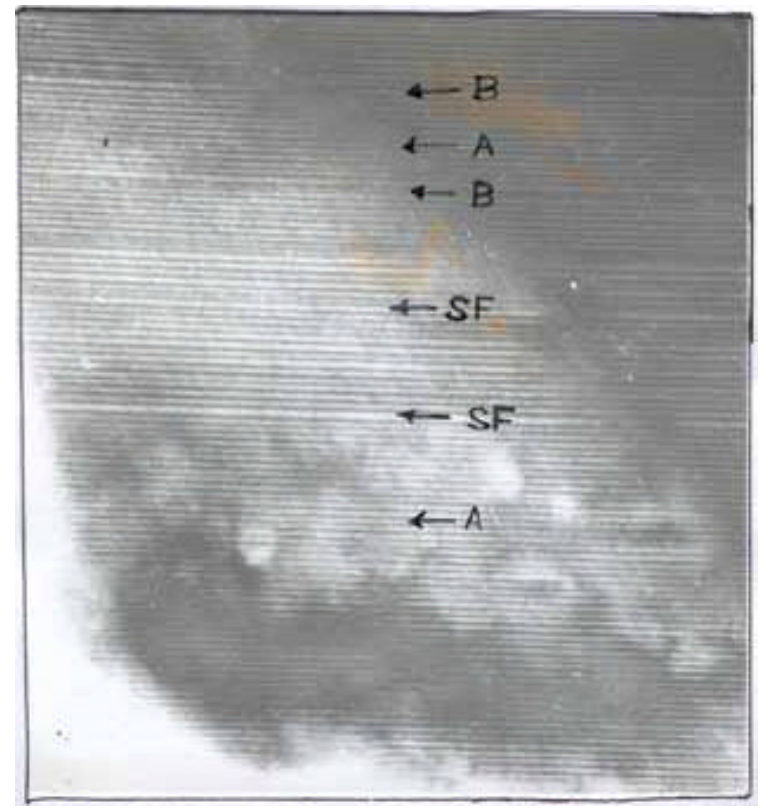

Figure 8. Lattice resolution TEM micrograph obtained from Y : 247 film. Notice the presence of some minority phase, Y : 124 (marked B) as also the stacking faults (marked SF).

Thus the as synthesized and processed Y : 247 films appear to embody native flux pinning centre which enhance the intragrain critical current density.

\section{Conclusions}

It can thus be concluded that in the present study, Y : 247 high temperature superconducting films with $T_{\mathrm{c}} \sim 73 \mathrm{~K}$ and $J_{\mathrm{c}} \sim 10^{3} \mathrm{~A} / \mathrm{cm}^{2}$ (for $\mathrm{Y}_{2} \mathrm{Ba}_{4} \mathrm{Cu}_{7} \mathrm{O}_{14+x}\left(\mathrm{Ag}_{0 \cdot 1}\right)$, the $J_{\mathrm{c}} \sim$ $10^{4} \mathrm{~A} / \mathrm{cm}^{2}$ ) have been successfully prepared through spray pyrolysis technique. The Y:247 phase has been retained through suitable quenching treatments in air or $\mathrm{LN}$, from the temperature $\sim 850^{\circ} \mathrm{C}$ representing the phase stability region of $\mathrm{Y}: 247$. From the local area structural and microstructural studies through TEM, it has been found that the as synthesized and processed films embody the minority $\mathrm{Y}: 124$ phase and stacking fault (SF) regions which have narrow widths compatible with coherence length, $\xi(\sim 30 \AA)$ and thus the as prepared films are expected to contain effective flux pinning sites.

\section{Acknowledgements}

The authors are grateful to Dr Vikram Kumar, Director, National Physical Laboratory, New Delhi, Prof. A R Verma and Prof. R P Rastogi for encouragement. They also thank Dr A V Narlikar, Dr T V Ramakrishnan, Professor G V Subba Rao and Professor S B Ogale for discussions. The authors acknowledge financial support from DST (PMB-NSTB) and UGC. 


\section{References}

Bordet P, Chaillout C, Chenarans J, Hodean J L, Marezio M, Karpinski J and Kaldis E 1998 Nature 334596

Deluca John A, Koras Pamela L, Tkaczyk J E, Bednarczyk Peter J, Garbauskas Mary F, Briant Clyde L and Sorensen Donald B 1993 Physica C205 21

Guptasarma P, Palkar V R, Multani M S, Vijayaraghavan R, Bendre Subhash T and Ogale S B 1991 Solid State Commun. 79851
Karpinski J, Rusiecki S, Kaldis E, Bucher B and Jilek E 1990 Physica C160 449

Karpinski J, Beeli C, Kaldis E, Wisard A and Jilek E 1998 Physica C830 153

Kumari Suman, Singh A K and Srivastava O N 1996 Superconduct. Sci. and Technol. 9405

Kumar D, Sharon M, Pinto R, Apte P R, Rai S P, Purandare S C, Gupta L C and Vijayaraghvan R 1993 Appl. Phys. 623522 Tallon J L, Pooke D M, Buckley R G and Presland M R 1990 Phys. Rev. B41 7220 